\title{
Thirty Years of the Journal
}

\author{
Institute of Economic Forecasting, Russian Academy of Sciences, Moscow, 117418 Russia \\ e-mail:b_porfiriev@mail.ru \\ Received June 15, 2020; revised June 17, 2020; accepted June 29, 2020
}

DOI: $10.1134 / \mathrm{S} 1075700720060155$

Our journal, dedicated to the analysis and forecasting of the socioeconomic development of Russia, celebrates its thirtieth anniversary. Over the years, the journal has gained solid credibility and a significant audience in our country. Its English version is published and distributed abroad, where the journal also finds an interested reader.

"Problemy Prognozirovaniya" (Studies on Russian Economic Development) is one of the main "brainchildren" of academician Yu.V. Yaremenko, who, being the director of the IEF RAS, considered it necessary to have a scientific publication at the Institute as a continuation and integral part of scientific research activity. Yu.V. Yaremenko laid the tradition of high requirements for the quality of publications, which involves the desire to perceive the national economy as an object of deep and comprehensive analysis, reliance on a developed economic and mathematical apparatus, and a high culture of working with statistics. The journal has supported this tradition to date.

Our publication publishes scientific works of domestic and foreign experts in the field of applied macroeconomic analysis and forecasting. A significant part of the journal's content is represented by the work of scientists of the Institute of Economic Forecasting of the Russian Academy of Sciences, who develop the school and traditions of the outstanding Russian economists, academicians A.I. Anchishkin, Yu.V. Yaremenko and V.V. Ivanter, long-term leaders of the Institute. The journal is one of the few scientific publications that has been striving to regularly publish long-term macrostructural forecasts developed at the Institute of Economic Forecasting of the Russian Academy of Sciences on the basis of a constantly improving economic and mathematical approach that allows analyzing systems of complex economic interactions.

The journal was founded in the early 1990s, when global changes occurred in the country's economy. Scientists and economists needed to analyze fundamentally new processes and at the same time new barriers, sometimes difficult to overcome, in particular, the gap in the statistics of time series that occurred in 1991. For this reason, in the 1990s there were relatively few publications devoted to long- or medium-term forecasting. Only in the second half of the 1990s, when the dynamic series of indicators of the Soviet and postSoviet periods were partially brought into a comparable form, did this research problem become less acute.
The economy that replaced the Soviet economy has become a pronounced recession economy. And among the first researchers who managed to uncover and formulate the root causes of the crisis, to build sound forecasts of economic dynamics, were the authors of "Problemy Prognozirovaniya."

A major scientific problem in these years was the shift in research emphasis: while in Soviet times economists had to work with material indicators to a greater extent, in the new conditions, cost aspects became paramount. Institutional relations began to fulfill a completely new function in the economy. The authors of the journal were able to promptly offer high-quality materials on both new financial realities and institutional problems.

In the 2000s, many difficulties of the 90 s were overcome. The time series of statistical data became longer and more correct and the level of uncertainty in the economy significantly decreased. The journal contains more and more professional texts about research, not only in macroeconomics, but also in the field of social development, science and technology, resource support, consumer demand, foreign economic relations, regional problems, etc. The publication of works on long-term macrostructural forecasting in this period occupies one of the central places.

The past years have been a time of integration of approaches of Russian scientists and their colleagues from Europe, the United States and Asian countries. The consequence of this was the publication in the journal of a large number of articles written by our foreign partners, as well as discussion materials with the participation of foreign scientists. The development of the Internet, the improvement of instruments for economic analysis fundamentally changed the methods and the speed of working with information. This contributed to an understanding of the factors of market uncertainty, the macroeconomic significance of unemployment and inflation, the deepening of knowledge about financial relationships, etc.

In the future, as in previous years, we will strive to give priority to articles prepared on the basis of real applied research, maintain independent judgments, adherence to discussions, and also attract young scientists capable of introducing into the journal's content a sense of the new economic reality.

\author{
Editor-in-Chief \\ Academician B.N. Porfiryev
}

